\title{
BMJ Open Case finding for dementia during acute hospital admissions: a mixed-methods study exploring the impacts on patient care after discharge and costs for the English National Health Service
}

Anne-Marie Burn, ${ }^{\oplus 1}$ Frances Bunn, ${ }^{\circ}$ Jane Fleming, ${ }^{\oplus 1}$ David Turner, ${ }^{3}$ Chris Fox, ${ }^{3}$ Alexandra Malyon, ${ }^{4}$ Carol Brayne ${ }^{1}$

To cite: Burn A-M, Bunn F, Fleming J, et al. Case finding for dementia during acute hospital admissions: a mixed-methods study exploring the impacts on patient care after discharge and costs for the English National Health Service. BMJ Open 2019;9:e026927. doi:10.1136/ bmjopen-2018-026927

- Prepublication history and additional material for this paper are available online. To view these files, please visit the journal online (http://dx.doi. org/10.1136/bmjopen-2018026927).

Received 26 September 2018 Revised 1 March 2019 Accepted 10 April 2019
Check for updates

(C) Author(s) (or their employer(s)) 2019. Re-use permitted under CC BY-NC. No commercial re-use. See rights and permissions. Published by BMJ.

For numbered affiliations see end of article.

Correspondence to Professor Frances Bunn; f.bunn@herts.ac.uk

\section{ABSTRACT}

Objective Between 2012 and 2017 dementia case finding was routinely carried out on people aged 75 years and over with unplanned admissions to acute hospitals across England. The assumption was that this would lead to better planning of care and treatment for patients with dementia following discharge from hospital. However, little is known about the experiences of patients and carers or the impacts on other health services. This study explored the impact of dementia case finding on older people and their families and on their use of services.

Design Thematic content analysis was conducted on qualitative interview data and costs associated with service use were estimated. Measures included the MiniMental State Examination, the EuroQol quality of life scale and a modified Client Service Receipt Inventory.

Setting Four counties in the East of England.

Participants People aged $\geq 75$ years who had been identified by case finding during an unplanned hospital admission as warranting further investigation of possible dementia and their family carers.

Results We carried out 28 interviews, including 19 joint patient-carer(s), 5 patient only and 4 family carer interviews. Most patients and carers were unaware that memory assessments had taken place, with many families not being informed or involved in the process. Participants had a variety of views on memory testing in hospital and had concerns about how hospitals carried out assessments and communicated results. Overall, case finding did not lead to general practitioner (GP) follow-up after discharge home or lead to referral for further investigation. Few services were initiated because of dementia case finding in hospital. Conclusions This study shows that dementia case finding may not lead to increased GP follow-up or service provision for patients after discharge from hospital. There is a need for a more evidence-based approach to the initiation of mandatory initiatives such as case finding that inevitably consume stretched human and financial resources.

\section{INTRODUCTION}

Pre-existing cognitive impairment in hospitalised older people is estimated at between

\section{Strengths and limitations of this study}

- This is one of the first studies to investigate the impacts of a mandatory policy introduced nationwide without prior piloting, feasibility testing or evidence of effectiveness-case finding for dementia among all hospital patients aged $\geq 75$ years whose admission was unplanned.

- Qualitative research methods using topic-guided interviews enabled in-depth exploration of personal experiences of dementia case finding both during a hospital stay and of health and care services used subsequently.

- As the focus was on those identified by case finding while in-patients, the study design sought to interview relatives/family carers as well as these former patients themselves.

- Study limitations include a small sample size and a reliance on participants' self-reporting of service use data.

- It was beyond the scope of this study to track actual service use costs so our cost estimation draws on published unit costs data.

$15 \%$ and $42 \% \cdot{ }^{1-5}$ Many of these patients may not have had a previous diagnosis of dementia. ${ }^{36}$ This has led to concerns about providing adequate care for older people with dementia, and policy development to improve the identification of dementia in older people in hospital. ${ }^{7-10}$ In the English National Health Service (NHS) initiatives were introduced to increase awareness and improve the identification of dementia in secondary care. ${ }^{11-14}$ In 2012-2013, the Department of Health introduced a mandatory policy requiring that all hospitals across England routinely carry out cognitive assessments with $\geq 75$-year olds who have had an emergency admission and that those identified as potentially having dementia are 
appropriately assessed and referred. The rationale for case finding in hospital was that early identification of cognitive impairment would lead to a timely diagnosis, informed patient care and improved health outcomes for older people. ${ }^{1516}$ This was implemented in the absence of any randomised controlled trial evidence to know the impact of such an approach.

Although cognitive assessment tests can detect undiagnosed dementia, ${ }^{17-19}$ dementia does not fit the criteria for screening programmes and there are concerns over the impacts of case finding as well as screening for dementia. ${ }^{20}{ }^{21}$ Moreover, in practice the distinction between screening and case finding is often not clear to clinicians and the public. ${ }^{22}{ }^{23}$ Healthcare professionals have been reported as viewing case finding as a financially and politically driven policy with little or no evaluation of patient outcomes. ${ }^{24-27}$ In a previous paper, we reported how the variation in approaches to dementia case finding has meant that information communicated to primary care is inconsistent and has an impact on how well general practitioners (GPs) can effectively plan patients' treatment and care once they are home in the community. ${ }^{27}$

Little is known about the wider impacts of dementia case finding on patient and carer experiences and on their access to dementia-related or other care services. The overall aims of this study were to explore the impacts of dementia case finding on older people identified by hospital case finding as warranting further investigation, their family carers and their use of health service and care services. For example, were they being reassessed in primary care and, if appropriate, receiving specialist referral, being given a diagnosis or receiving new services?

\section{METHODS}

This study involved in-depth exploratory interviews with former hospital patients and their family carers. A range of qualitative and quantitative data was collected. This was the second phase of the CASCADE study (CASe finding in hospitals-impacts on CAre for people with DEmentia). ${ }^{28}$ Phase I results are reported in full elsewhere. ${ }^{27}$

We recruited former patients of two participating hospitals in the East of England. Eligible patients were aged at least 75-year olds, had been acutely admitted 6-12 months previously, had been flagged by dementia case finding as warranting further investigation about their cognition and were community dwelling. Family carers of these patients were also recruited for interviews. Invitation letters were sent to eligible participants from the hospital elderly medicine consultant under whose care they had been admitted, together with an information sheet and response form.

Semistructured interview schedules were developed to gather patient and family carers' experiences and perceptions of dementia case finding and the impacts of case finding on their subsequent treatment and care (online supplementary file 1). Demographic data were collected and the Mini-Mental State Examination $(\mathrm{MMSE})^{29}$ and EuroQol (EQ-5D-5L) ${ }^{30}$ validated scales were used to characterise patients' cognition and health-related quality of life, respectively. For the analysis, those with a score below 24 on the MMSE were classified as cognitively impaired and those with a score of 24 and above were categorised as cognitively intact. EuroQol's validated proxy version of the EQ-5D-5L was undertaken with carers to characterise patients in the minority of cases when a carer were interviewed separately from the former patient. Completed EQ-5D-5Ls were scored against the published algorithm and results from the scale's five domains were used to characterise participants' levels of difficulty in each. ${ }^{31}$ Data were collected on patients' self-reported use of inpatient and outpatient services, day activity services since the index hospital admission, community care services and current medication. Service use was collected using relevant sections of the Client Service Receipt Inventory (CSRI) ${ }^{32}$ using 'Visio' timelines $^{33}$ to facilitate recall and recording of events such as referrals or the start of new services. Two female researchers $(\mathrm{A}-\mathrm{MB}, \mathrm{JF})$ carried out the interviews in the patients' and family carers' homes across four counties in the East of England (Bedfordshire, Cambridgeshire, Essex and Hertfordshire). Interviews lasted about an hour. Participants gave signed consent before the interview and interviews were tape recorded, transcribed and anonymised.

An initial thematic framework was developed by the research team (A-MB, FB, JF) which was informed by the research questions and coding a selection of transcripts. The codeframe and the anonymised transcripts were transferred into NVivo V.11 and the data analysed using thematic content analysis. ${ }^{34}$ This enabled the key features of patients' and carers' experiences to be elicited from the data. Quantitative data were entered into an Excel spreadsheet.

\section{Estimation of service costs}

Service use, reported by means of the modified CSRI, were costed using several sources. For community-based healthcare, we obtained cost per hour of staff time from a published source of unit cost data. ${ }^{35}$ Estimates of average contact time and the proportion of healthcare professionals time that would be spent on direct client contact were used to estimate a cost per contact. ${ }^{36}$ For some contacts respondents reported frequency rather than numbers of contacts, for example, three times a week. To convert this to numbers of contacts we required a time period, this was taken as the time difference between the date of discharge and the date of the interview. This duration therefore varied between individuals.

Costs for secondary care were obtained from NHS references costs. ${ }^{37}$ For elective inpatient admissions, we used a weighted average of either elective short stays or long stays. This gave estimates for the costs of elective stages of $£ 616$ for an elective short stay and $£ 3058$ for an elective long stay. For non-elective admissions, again a weighted 
average was obtained from NHS references costs, this was $£ 3058$ for long stays. For accident and emergency visits, a weighted average of $£ 204$ was used. A detailed estimate of the cost of memory services was available from the literature. $^{35}$ This gave a cost per client of $£ 1218$. However, this was based on a different NHS trust and it is not clear how representative this would be of the service provided to participants in the current study. For memory-related drugs, a price was obtained from a published source. ${ }^{38}$ All costs are in UK pound sterling for the year 2015/2016. As the period of analysis was for 1 year only discounting was not used.

\section{PATIENT AND PUBLIC INVOLVEMENT}

Two well-established patient and public involvement groups were involved in the study; the University of Hertfordshire Patient Involvement in Research Group, and the University of Cambridge's Public Involvement in Research into Ageing and Dementia Group. Four members of these groups acted as a User Reference Group for the study. They provided feedback on the aims of the study, study documents such as patient information sheets, and commented on preliminary findings from the qualitative analysis.

\section{FINDINGS}

We conducted a total of 28 interviews involving 49 participants. Of those, 24 were former patients who had been identified as having a concern about their memory during an unplanned hospital admission and 25 were carers. Nineteen interviews were held jointly with the patient and their family carer(s). All patients had received a memory assessment during their hospital stay which indicated that there was a cause for concern over their cognition which warranted further investigation.

Table 1 summarises descriptive characteristics of the former patients in our study. Both their median and mean age was 85 (range 79-94) and just over half (53\%) were women. The median MMSE score was 23.0 (IQR 16.5-26) indicating mild cognitive impairment, but there was considerable variation with scores ranging between 6 and 30. Patients had considerable levels of physical impairment and difficulty with activities of daily living, for example, nearly half were unable to walk and over a third had severe problems washing and dressing themselves. The EQ-5D-5L scoring system ${ }^{31}$ can provide scores between 1 and -0.594 . This range has anchor points where 1 is considered to be full health and 0 is considered to be equivalent of dead. The scoring algorithm allows some scores to be $<0$, that is, worse than dead. Twenty-four former patients provided a value for their own health state and the mean value for these individuals was 0.39 ( $95 \%$ CI 0.25 to 0.52 ). There were 25 carers who provided a valuation of their own health with a mean value 0.78 (95\% CI 0.69 to 0.86 ). For comparison, population norms are available for those aged over 75 years

\begin{tabular}{|c|c|}
\hline Full sample & $\mathrm{n}=\mathbf{2 8}$ \\
\hline \multicolumn{2}{|l|}{ Age } \\
\hline Mean and median & 85,85 \\
\hline Range & $79-94$ \\
\hline$\%$ Female MMSE & $53 \%$ \\
\hline $\begin{array}{l}\text { Median (IQR) } \\
\text { Mean (SD) }\end{array}$ & $\begin{array}{l}23(16.5-26) \\
20.8(6.8)\end{array}$ \\
\hline Sample with EQ-5D-5L & $\mathrm{n}=24$ \\
\hline $\begin{array}{l}\text { Severe problems walking/ } \\
\text { unable to walk }\end{array}$ & $44 \%$ \\
\hline $\begin{array}{l}\text { Severe problems washing } \\
\text { and dressing self/unable to } \\
\text { wash \& dress self }\end{array}$ & $37 \%$ \\
\hline $\begin{array}{l}\text { Severe problems doing } \\
\text { usual activities/unable to do } \\
\text { usual activities }\end{array}$ & $52 \%$ \\
\hline $\begin{array}{l}\text { Severe/extreme pain or } \\
\text { discomfort }\end{array}$ & $4 \%$ \\
\hline $\begin{array}{l}\text { Severely/extremely anxious } \\
\text { or depressed }\end{array}$ & $15 \%$ \\
\hline $\begin{array}{l}\text { EQ-5D-5L valuation } \\
(95 \% \mathrm{Cl})\end{array}$ & 0.39 (0.25 to 0.52$)$ \\
\hline
\end{tabular}

EQ-5D-5L, EuroQol; MMSE, Mini-Mental State Examination.

for the EQ-5D-3L ${ }^{39}$ which give values of 0.75 and 0.71 for males and females, respectively. The value obtained here for former patients is considerably below these values.

\section{IMPACTS OF DEMENTIA CASE FINDING ON SERVICE USE}

Nine people had been assessed postdischarge either in a memory clinic or by an old age psychiatrist but two of these had already been referred by their GP prior to hospital admission. For the seven people who had been referred to memory services since hospital discharge it was not clear whether these referrals were a result of hospital case finding or not. Patients referred for investigation since discharge $(n=7)$ generally had lower MMSE scores than those not referred (MMSE of 17 (IQR 15-22) versus 25 (IQR 19-26)). In the non-referred group, two patients had MMSE scores that indicated severe cognitive impairment and five had scores indicating moderate cognitive impairment. Five patients who were referred since case finding had been started on dementia medication (eg, donepezil, memantine), but two of these had stopped taking this medication within a fortnight because of side effects.

Estimates of the costs incurred by former patients of dementia case finding for the period between index stay discharge and interview are given in table 2 . We had available data for 28 former patients, 24 where the patient was present at interview and 4 where only a carer was present. Precise costing was not generally possible, so these costs should be taken as indicative. This group have a mean 


\begin{tabular}{|c|c|c|}
\hline Service category & Mean cost & $95 \% \mathrm{Cl}$ \\
\hline Inpatient stays & $£ 699$ & $£ 47$ to $£ 1351$ \\
\hline Outpatient visits & $£ 767$ & $-£ 113$ to $£ 1646$ \\
\hline Day service use & $£ 116$ & -£37 to £269 \\
\hline $\begin{array}{l}\text { Community care } \\
\text { contacts }\end{array}$ & $£ 3539$ & $£ 1419$ to $£ 5658$ \\
\hline $\begin{array}{l}\text { Cost of memory- } \\
\text { related drug }\end{array}$ & $£ 60$ & $-£ 16$ to $£ 136$ \\
\hline Total & $£ 5180$ & $£ 2394$ to $£ 7967$ \\
\hline
\end{tabular}

estimated cost of $£ 5180$ (95\% CI £2394 to £7967) in the period following the index stay. There is also considerable uncertainty around these cost estimates as indicated by the CIs. The major drivers of cost were inpatient and outpatient services, district nursing and home care worker. Comparatively few costs were specifically related to cognitive services, apart from memory clinics and some spending on memory-related drugs. There was also one
GP home visit that was specified as related to memory assessment.

Two main themes emerged from the qualitative analysis (1) attitudes and experiences of dementia case finding and (2) patients' and carers' follow-up experiences. Examples quotes $(\mathrm{Q}=$ quotes $)$ are given in tables 3 and 4 .

\section{Attitudes and experiences of dementia case finding}

Patients and carers were often unaware that memory assessments had taken place during their hospital admission and, in many cases, the patient had been assessed alone without a family carer being present or notified (Q1-2). For those carers who were aware of the memory assessment, they lacked information about the purpose or outcome of the test.

Although some patients and carers did not mind having a memory test in hospital (Q3), others felt that it was inappropriate to conduct such tests when someone was acutely ill (Q4-6, 9-10). Some patients reported feeling anxious about answering the memory questions incorrectly $(Q 7, Q 8)$. There were examples of poor practice in terms of the way the test had been administered, such

\section{Table 3 Quotes illustrating theme 1 \\ Quote Views and experiences of dementia case finding}

$1 \quad$ I think someone did come to see him but they didn't see me. (Carer 16)

2 I don't think that was on his release papers neither 'cos they usually put things that he's had done on his release papers. (Carer 04)

3 Didn't worry me one bit. (Patient 21)

$4 \quad$...if there's no medication or they're not going to put you on treatment what's the point. That's my view. (Carer 03)

$5 \quad$ I thought it very inappropriate when somebody's in and they're feeling really rough, their breathing is dreadful, full of pneumonia and all the rest of it (Carer 08)

6 at two o'clock in the morning... We'd been in A\&E for hours... They decided that Dad should stay because he had an infection, and they gave him the memory test...I remember saying, 'You are having a laugh'. (Carer 26)

7 you feel as though they're encroaching on your brain to try and make you make a mistake, that's how I felt. (Patient 05)

8 [about the test] ...he was shattered, and I think he was frightened. (Carer 26)

9 I would have thought that if there were to be any benefit gained it would be once the patient is stable. At admission, everything's frightening, worrying, they don't know what they're there for maybe or they're worried about what they're there for. (Carer 23)

10 I explained it, she's more aware at home, I explained how bad she was in hospital to how different she is at home. (Carer 02)

11 .... doctor came in and she asked [patient] some questions and of course [patient] just doesn't always understand because it's the comprehension isn't it, cognitive as well, and so [patient] said, 'ask my wife', and she said, 'I am asking you' [said in an abrupt manner] which made me prickle so I said, 'well, [patient]'s dysphasic and you know, he does have difficulty....and I was really cross about that, I thought time and place'. (Carer 08)

12 Well I was a little bit confused really over the whole thing, you know, well I think the family were really. (Carer 01)

13 I think they were just telling me that I had to get her to the doctors, to organise the Memory Clinic, I'm sure that's what it was, they were telling me, but it wasn't really clear, like I'm saying, I think she should have been sent home with some paperwork to say right, this is what is needed. (Carer 02)

14 they changed her medication and they stopped that, so there must have been a reason for stopping it...but they didn't tell us, we had no way of knowing until three months later, which I think is frightening. (Carer 23)

15 they were in a rush to get her out because she didn't need any more treatment, albeit she was discharged taking an antibiotic and there was no indication what the antibiotic was for, or anything on the, it wasn't included on the medications list. (Carer 07) 
Table 4 Quotes illustrating theme 2

\section{Quote}

16

17

18

19

20

21

22

23

24

25

\section{Patients' and carers' follow-up experiences}

Well I mean, I'm a bit surprised that the GP hasn't been to see her. (Carer 01)

I don't feel the GP's that interested. (Carer 16)

I did, I prompted it. So how did you prompt it, what happened? Alright, I... I told the GP that she needs this test. (Carer 06)

No, that was me ... [raised wife's memory after unrelated GP visit] That was a good while ago and he's never mentioned anything since. (Carer 20)

I'd asked his GP if he could have a psychiatric assessment and they sent round a CPN and she chatted to him and she said to me 'oh yes, he has got dementia', she said 'I'm not quite sure what type, l'll discuss it with the team' because the consultant was away at that time 'and we'll let you know'. Well she never did get back to me. (Carer 16)

so why is it not dealt with in the hospital when they're actually there, and they can see there's a problem. (Carer 02)

I think it works well, like I said, it works well too that I've kind of got a bit of my life back...it definitely helps having carers three times a day. (Carer 02)

We could not have managed without it. We were getting desperate-we could not manage, we couldn't be there for long enough. (Carer 14)

It's not care, they just come in, write a bit in her folder and that is it, that is not care, they do not look after my mum. (Carer 05) they come at so weird times. I mean, for instance, the other Sunday night they came at twenty past five to put her to bed. Have you ever heard of anything so stupid! (Carer 01) as the test being administered in an insensitive manner (Q11). Even when case finding had flagged up a concern about a patient's cognition this did not appear to have impacted on discharge planning or the involvement of carers (Q12, Q13). For example, patients were being discharged with altered medication and the hospital did not inform the family carers (Q14, Q15).

\section{Patients and carers' follow-up experiences}

There was a consistent pattern for patients and relatives in terms of their follow-up experiences. Most reported that they had not had a follow-up discussion with their GP about the dementia case finding outcomes or reassessment of their cognition postdischarge (Q16, Q17). Even though some had seen a GP or practice nurse since leaving hospital, they reported that the issue of dementia case finding had not been raised (Q18). Some carers contacted their GP about their relative's memory but felt the follow-up was not always adequate (Q19-Q20). One carer could not understand why the hospital did not deal with their relative's memory problem since they had identified it and felt this was another issue for carers to take on board (Q21).

Dementia case finding did not appear to have impacted on service provision postdischarge. Relatively few new services appeared to have been instigated and others, such as Occupational Therapy (OT) assessments and adjustments to the home, were not timely. While some families reported satisfaction with social care services, such as respite care $(\mathrm{Q} 22)$, many others felt their needs were not being met. For example, carers coming at inappropriate times and the provision of poor care (Q23-Q25).

\section{DISCUSSION}

Dementia case finding in acute hospitals involves the routine cognitive assessment of older people during an unplanned hospital stay and aims to improve the identification of patients with dementia in hospitals so that they could be flagged to their GP for further investigation and referral. This study aimed to explore patients' and their families' experiences of how this worked in practice. It was conducted in two acute hospital settings in the East of England where dementia case finding was implemented with little or no evaluation of its effectiveness in terms of improving patient outcomes. To our knowledge, this is the first study to explore the views and experiences of older patients and their family carers to case finding and to estimate the economic impact for the health service.

We spoke to patients and carers of patients who had been identified as having a concern about their cognition 
during their hospital admission. Although the median MMSE score of included participants at interview indicated that most patients had mild cognitive impairment, MMSE scores ranged from 6 to 30. The findings from this study suggest that there was little follow-up from patients' GPs postdischarge and few further investigations or referrals or medication instigated due to dementia case finding outcomes; although in some cases, patients had already been seen by their GP prior to their hospital stay about their cognition. The lack of follow-up may not be surprising in light of the fact the outcomes of dementia case finding are often poorly reported to GPs. ${ }^{27}$

Patients and their families had mixed attitudes towards dementia case finding but many did not remember the assessment and/or did not appear to have been informed about what this would mean in terms of their subsequent care and treatment. There was also concern that the acute hospital setting might not be the best place in which to assess cognition. Indeed, 10 former patients had MMSE scores which indicated no cognitive impairment despite having been picked up by the case finding process when in hospital. In a previous paper, we reported that dementia case finding has raised awareness about dementia within hospitals. ${ }^{27}$ However, delirium is often undetected in hospitals $^{40}$ and can increase the likelihood of reporting false positives and result in misdiagnosis of dementia. ${ }^{41}$

The results of the costing evaluation showed that participants/patients had average costs of $£ 5180$. The mean length of time over which these costs were incurred was 283 days, excluding the initial stay. Although these individuals had been identified from dementia case finding, the proportion of those costs attributed directly to services related to cognition appear to be small $(\sim 6 \%)$. This is not surprising as we found that few services had been instigated due to case finding. While the costs of services initiated in the community following case finding did not appear to be high, from health professionals' reports of how case finding has been implemented in the previous phase of the CASCADE study ${ }^{27}$ it is likely that case finding is associated with significant costs within the hospital itself, though to our knowledge no research to date has quantified these yet. This suggests that an evaluation of the costs of such a policy, including the opportunity costs within the policy implementations system (Public Health England, NHS England) are warranted.

\section{Limitations}

The small sample size and the reliance on participants' self-reporting are limitations of the study. Recruiting in this setting is challenging and only a small proportion of those who have experienced hospital case finding could be consulted for the study and may not be representative of the patient group even within the single settings. Patients found it difficult to correctly recall services received and the reason for those services. Therefore, it was difficult to judge whether services received were a direct consequence of dementia case finding. Carers were responsible for coordinating their relative's care and consequently carers were able to provide more information than patients. The participants in this study may not be representative of others elsewhere in the UK, although no other such study has taken place to our knowledge. Since presentation of our findings to key policy makers the mandatory nature and financial incentives associated with dementia case finding are no longer in place. The study remains relevant as moves to promote case finding across health settings affect many countries and it serves as an illustration of the vital need to test policies before implementing them on the large scale. ${ }^{42} 43$

\section{CONCLUSIONS}

This study highlights that dementia case finding in hospitals did not necessarily lead to a GP follow-up or referrals for further investigation or lead to new supportive services being put in place. Often patients and their family carers were not informed that memory assessments had been carried out while in hospital or what the outcomes of the assessment would mean in terms of their future care and treatment. There is a need for a more evidence-based approach to the initiation of mandatory initiatives such as case finding. This includes evaluation of the costs of such a policy, including the opportunity costs within the policy implementations system.

\section{Author affiliations}

${ }^{1}$ Cambridge Institute of Public Health, University of Cambridge School of Clinical Medicine, Cambridge, Cambridgeshire, UK

${ }^{2}$ Centre for Research in Public Health and Community Care, University of Hertfordshire, Hatfield, Hertfordshire, UK

${ }^{3}$ Norwich Medical School, University of East Anglia Faculty of Medicine and Health Sciences, Norwich, Norfolk, UK

${ }^{4}$ Addenbrooke's Hospital, Cambridge University Hospitals NHS Foundation Trust, Cambridge, Cambridgeshire, UK

Acknowledgements The authors would like to thank all the participants in this study and Dr Catherine Rippingale, Dr Stephen Wallis, Rizaldy Tibio, Alice Robertson and Sara Jones for assisting in recruitment and their input through the Study Advisory Group. The authors would also like to thank Ms Marion Cowe, Dr Paul Millac, Mr Barry Plumpton and Mr John Willmott, members of the Patient Involvement in Research Group at the University of Hertfordshire who acted as the User Reference Group for the study.

Contributors JF, FB, DT, CF, CB wrote the protocol. AM commented on the protocol, assisted with recruitment and commented on the paper. JF and A-MB collected the data. A-MB, JF, DT, FB analysed the data. A-MB, FB, JF and DT wrote the first draft of the manuscript. All authors contributed to the writing of the manuscript and approved its content. FB (the manuscript's guarantor) affirms that the manuscript is an honest, accurate and transparent account of the study being reported; that no important aspects of the study have been omitted; and that any discrepancies from the study as planned have been explained.

Funding This article paper presents independent research funded by the National Institute for Health Research (NIHR) Collaboration for Leadership in Applied Health Research \& Care (CLAHRC) East of England, at Cambridgeshire and Peterborough NHS Foundation Trust.

Disclaimer The views expressed are those of the author(s) and not necessarily those of the NHS, the National Institute of Health Research (NIHR) or the Department of Health and Social Care.

Competing interests None declared.

Patient consent for publication Not required.

Ethics approval Ethical approval was obtained from South Central—Oxford C Research Ethics Committee (reference:15/SC/0728). 
Provenance and peer review Not commissioned; externally peer reviewed.

Data sharing statement № additional data are available.

Open access This is an open access article distributed in accordance with the Creative Commons Attribution Non Commercial (CC BY-NC 4.0) license, which permits others to distribute, remix, adapt, build upon this work non-commercially, and license their derivative works on different terms, provided the original work is properly cited, appropriate credit is given, any changes made indicated, and the use is non-commercial. See: http://creativecommons.org/licenses/by-nc/4.0/.

\section{REFERENCES}

1. Boustani M, Baker MS, Campbell N, et al. Impact and recognition of cognitive impairment among hospitalized elders. J Hosp Med 2010;5:69-75.

2. Sampson EL, Blanchard MR, Jones L, et al. Dementia in the acute hospital: prospective cohort study of prevalence and mortality. $\mathrm{Br} J$ Psychiatry 2009;195:61-6.

3. Timmons S, Manning E, Barrett A, et al. Dementia in older people admitted to hospital: a regional multi-hospital observational study of prevalence, associations and case recognition. Age Ageing 2015;44:993-9.

4. Mukadam N, Sampson EL. A systematic review of the prevalence, associations and outcomes of dementia in older general hospital inpatients. Int Psychogeriatr 2011;23:344-55.

5. Travers C, Byrne G, Pachana N, et al. Prospective observational study of dementia and delirium in the acute hospital setting. Intern Med J 2013;43:262-9.

6. Briggs R, Dyer A, Nabeel S, et al. Dementia in the acute hospital: the prevalence and clinical outcomes of acutely unwell patients with dementia. QJM 2017;110:33-7.

7. Alzheimer's Society. Counting the cost: caring for people with dementia on hospital wards, 2009.

8. NHS Confederation. Acute Awareness - improving hospital care for people with dementia, 2010.

9. Royal College of Psychiatrists, Care Quality Commission. 2017. National Audit of Dementia Care in General Hospitals 20162017 Third Round of Audit Report.

10. Royal College of Psychiatrists. In: Young J, Hood C, Gandesha A eds. et al National Audit of Dementia care in general hospitals 201213 (Second round audit report and update. HQIP, London, 2013.

11. Department of Health. Using the Commissioning for Quality and Innovation (CQUIN) payment framework: Guidance on new national goals for 2012-13. 2012

12. NHS Commissioning Board. Commissioning for quality and innovation (CQUIN): 2013/14 guidance, 2012.

13. NHS England. Commissioning for quality and innovation (CQUIN): 2014/15 guidance, 2014.

14. NHS England. Commissioning for Quality and Innovation (CQUIN) Guidance for 2015/16, 2015.

15. NICE (National Institute for Health and Care Excellence). Dementia: supporting people with dementia and their carers in health and socia care. Clinical Guideline CG42, 2006.

16. NICE (National Institute of Health and Care Excellence). Dementia: Independence and wellbeing. Quality Standard QS30, 2013

17. Mitchell AJ, Malladi S. Screening and case-finding tools for the detection of dementia. Part II: evidence-based meta-analysis of single-domain tests. Am J Geriatr Psychiatry 2010;18:783-800.

18. Jackson TA, Naqvi SH, Sheehan B. Screening for dementia in general hospital inpatients: a systematic review and meta-analysis of available instruments. Age Ageing 2013;42:689-95.

19. Jackson TA, MacLullich AM, Gladman JR, et al. Diagnostic test accuracy of informant-based tools to diagnose dementia in older hospital patients with delirium: a prospective cohort study. Age Ageing 2016;45:505-11.
20. Boustani M, Peterson B, Hanson L, et al. U.S. Preventive Services Task Force. Screening for dementia in primary care: a summary of the evidence for the U.S. Preventive Services Task Force. Ann Intern Med 2003;138:927-37.

21. Brayne C, Fox C, Boustani M. Dementia screening in primary care: is it time? JAMA 2007;298:2409-11.

22. McCartney M. "Case finding" in dementia is simply screening with no evidence of benefit. BMJ 2014;349:g4791.

23. Ranson JM, Kuźma E, Hamilton W, et al. Case-finding in clinical practice: An appropriate strategy for dementia identification? Alzheimers Dement 2018;4:288-96.

24. Le Couteur DG, Doust J, Creasey $\mathrm{H}$, et al. Political drive to screen for pre-dementia: not evidence based and ignores the harms of diagnosis. BMJ 2013;347:f5125.

25. Reynish EL, Hapca SM, De Souza N, et al. Epidemiology and outcomes of people with dementia, delirium, and unspecified cognitive impairment in the general hospital: prospective cohort study of 10,014 admissions. BMC Med 2017;15:140.

26. Jackson TA, Gladman JR, Harwood RH, et al. Challenges and opportunities in understanding dementia and delirium in the acute hospital. PLoS Med 2017;14:e1002247.

27. Burn AM, Fleming J, Brayne C, et al. Dementia case-finding in hospitals: a qualitative study exploring the views of healthcare professionals in English primary care and secondary care. BMJ Open 2018;8:e020521.

28. Sampson EL, Leurent B, Blanchard MR, et al. Survival of people with dementia after unplanned acute hospital admission: a prospective cohort study. Int J Geriatr Psychiatry 2013;28:1015-22.

29. Folstein MF, Folstein SE, McHugh PR. "Mini-mental state". A practical method for grading the cognitive state of patients for the clinician. J Psychiatr Res 1975;12:189-98.

30. Herdman M, Gudex C, Lloyd A, et al. Development and preliminary testing of the new five-level version of EQ-5D (EQ-5D-5L). Qual Life Res 2011;20:1727-36.

31. van Hout $B$, Janssen MF, Feng $Y S$, et al. Interim scoring for the EQ$5 \mathrm{D}-5 \mathrm{~L}$ : mapping the EQ-5D-5L to EQ-5D-3L value sets. Value Health 2012;15:708-15.

32. Thornicroft G, et al. CSRI (Client Services Receipt Inventory) European version. International outcome measures in mental health, 2006. Royal College of P.

33. Momen N, Kendall M, Barclay S, et al. Using timelines to depict patient journeys: a development for research methods and clinical care review. Prim Health Care Res Dev 2013;14:403-8.

34. Coffey A, Atkinson P. Making sense of qualitative data: Complementary research strategies: Sage Publications Inc, 1996.

35. Curtis L, Burns A. Unit Costs of Health and Social Care 2016: Personal Social Services Research Unit. Canterbury: University of Kent, 2016.

36. Curtis L, Burns A. Unit Costs of Health and Social Care 2010 Personal Social Services Research Unit. Canterbury: University of Kent, 2010.

37. Do H. NHS Reference costs 2015-16: London Department of Health, 2016.

38. Somme D, Trouve H, Dramé M, et al. Analysis of case management programs for patients with dementia: a systematic review. Alzheimers Dement 2012;8:426-36.

39. Kind PHG, Macran S. UK Population norms for EQ-5D. Discussion Paper 172: York Uo: York, 1999.

40. Collins N, Blanchard MR, Tookman A, et al. Detection of delirium in the acute hospital. Age Ageing 2010;39:131-5.

41. Griffiths A, Knight A, Harwood R, et al. Preparation to care for confused older patients in general hospitals: a study of UK health professionals. Age Ageing 2014;43:521-7.

42. Brooker D, La Fontaine J, Evans S, et al. Public health guidance to facilitate timely diagnosis of dementia: ALzheimer's COoperative Valuation in Europe recommendations. Int J Geriatr Psychiatry 2014:29:682-93.

43. Alzheimer Cooperative Valuation in E. 2013. The European Joint Action on Dementia ALCOVE Synthesis Report. 